\title{
Detection of loose rivets in aeroplane components using lockin thermography
}

\author{
by Th. Zweschper ${ }^{1}$, D. Wu ${ }^{2}$ and G. Busse ${ }^{1}$ \\ ${ }^{1}$ Institut für Kunststoffprüfung und Kunststoffkunde.(IKP), Universität Stuttgart, Pfaffenwaldring 32, \\ D-70569 Stuttgart, Germany \\ ${ }^{2}$ Now at Robert Bosch GmbH, Postfach 13 09, D-73243 Wernau (Neckar), Germany
}

\begin{abstract}
Lockin thermography with its capability to monitor modulated heat flow in large areas (several $\mathrm{m}^{2}$ ) within a few minutes is applied to the rapid and remote inspection of aircraft structural components.

While some of our earlier work was devoted to the detection of subsurface structures and defects such as impact damages, delaminations, and hidden corrosion areas, we investigate in this paper how well the method is applicable to monitor the tightness of mechanical joints such as screws, rivets, and bolts.
\end{abstract}

\section{Introduction}

The operation of safety relevant structures (e.g. aerospace equipment and vehicles) requires reliable inspection techniques where defect areas are detected early enough to prevent catastrophic failure. As many structures still consist of metal, the rapid and remote identification of loose rivets is a topic of major concern. Therefore a method is needed that is applicable during inspection procedures to monitor the integrity of structures.

The purpose of this paper is to show that optical lockin thermography (OLT) /1-5/ can be used for such inspections. The basic idea is that remotely generated heat transport is sensitive to the metal/metal contact in the compressive area around screws or rivets.

Lockin thermography with optical excitation is a multiplex photothermal technique where modulated heat is generated in the surface of a sample by absorption of intensity modulated radiation. The resulting temperature modulation propagates as a thermal wave which causes a modulation of thermal emission. Therefore an infrared detector is a good thermal wave detector, and a thermography camera tuned to the modulation frequency of the radiation allows for phase angle imaging of the local delay between energy deposition and temperature change $14,5 /$. The change of heat contact caused by the compressive stress around the rivet can therefore be revealed by the phase angle image.

\section{Experimental arrangement}

The experimental arrangement shown in fig. 1 is similar to the one used before for other investigations with OLT $14,5 \%$. In order to provide adjustable different levels of compression we simulated rivets by screws fastened at different levels of torque. Thereafter the screws were replaced by an array of blind rivets. Illumination was achieved by lamps whose time dependence of radiation was controlled by the OLT system at a frequency of $0.06 \mathrm{~Hz}$. The time for one image was typically about 3-4 minutes.

\section{Results}

Experiments were first performed on model samples where the effect of rivets was simulated in a reproducible and adjustable way by screws. After the applicability of the method had been established the measurements were extended to riveted model samples and then to realistic riveted components. Results of the different stages are reported separately in the following. 


\subsection{Model samples}

Fig.2a is the phase angle image obtained on an array of 6 screws tightened at different torque levels. The phase angle along lines through the centres of the screws (fig. $2 \mathrm{~b}$ ) shows that the height of phase maxima correlates with the applied torque. The evaluation for two different screw sizes (M8 and M10, fig.2c) confirms that signal phase is suited as an indicator for the achieved compressive stress around the screws. If such a dependence is intended as a calibration curve, one must keep in mind that it is highly specific for the size of the screw and for the thickness and the material of the plates.

When we had shown that different levels of compressive stress can be determined remotely with OLT (a result which is of interest not only for model samples, but also for applications where all screws have to be tightened in the same way), a similar array consisting of 10 blind rivets was investigated. Different levels of compression were achieved by modifications of the cross section of the breaking point from 1.13 up to $3.32 \mathrm{~mm}^{2}$. The result (fig. 3a) shows the differences though the cross section is only a qualitative indicator. The evaluation gives the curve of fig. $3 \mathrm{~b}$ where the cross section is related to the maximum of phase angle. The change of slope as compared to fig. 2 is a consequence of the change of material (aluminium instead of nickelised steel) and of plate thickness $(1.5 \mathrm{~mm}$ instead of $2 \mathrm{~mm}$ ) /6-9/.

In order to find out whether the effect of excessive mechanical stress can be detected, OLT images were taken before the sample was exposed to tensile stress and thereafter. The result presented in fig. 4 clearly indicates the difference. So it has been proved that damage caused by excessively loading riveted joints can be revealed rapidly and in a remote way.

\subsection{Real samples}

A circular cover provided with 10 rivets was inspected after two rivets (nr. 4 and $\mathrm{nr} .5$ in fig.5) had been loosened by purpose from the rear surface. The surprising result is that the signal obtained for these two rivets has the same level as the one of rivet no. 10, which was not modified. So we have to conclude that this rivet also provides only a reduced compressive stress. This is an example where a defect could be discovered that had not been built in before. A linear arrangement of rivets is seen on the aeroplane component in fig.6. Some of the rivets had again be loosened by purpose from the rear surface. Their phase signal in the OLT image differs clearly from the one of the other rivets thereby revealing the loss of compression stress.

\section{Conclusion}

The results of our feasibility study performed with OLT indicate that one can locate screws and rivets which provide only a reduced stress. Also the effect of excessive load on rivet compression could be established. This result should be of interest for inspection and maintenance of safety relevant structures.

However, there are still some problems to be solved in further investigations:

- Corrosion effects might be superposed. Though they are dangerous as well, it is important to separate them from loss of compressive stress.

- Rivets do not always consist of the same material. Loss of compression should be detectable independently of the material effect. This is of particular importance if the rivets are hidden under paint.

\section{REFERENCES}

[1] CARLOMAGNO (G. M.), BERARDI (P. G.) - Unsteady thermography in nondestructive testing, Proceedings of the 3rd Biannual Information Exchange, Aug.24-26, St. Louis/USA, 1976, p. 33-39. 
[2] BEAUDOIN (J.-L.), MERIENNE (E.), DANJOUX (R.), EGEE (M.) - Numerical system for infrared scanners and application to the subsurface control of materials by photothermal radiometry, Infrared technology and applications, SPIE 590, 1985, p. 287-292.

[3] KUO (P. K.), FENG (Z. J.), AHMED (T.), FAVRO (L. D.), THOMAS (R. L.), HARTIKAINEN (J.) - Parallel thermal wave imaging using a vector lockin video technique, Hess P., Pelzl J. (Eds.), Photoacoustic and photothermal phenomena, Springer-Verlag, Heidelberg, 1987, p. 415-418.

[4] BUSSE (G.), WU (D.), KARPEN (W.) - Thermal wave imaging with phase sensitive modulated thermography, J. Appl. Phys. 71, 1992, p. 3962-3965.

[5] WU (D.), SALERNO (A.), MALTER (U.), AOKI (R.), KOCHENDÖRFER (R.), KÄCHELE (P. K.), WOITHE (K.), PFISTER (K.), BUSSE (G.) - Inspection of aircraft structural components using lockin-thermography. Busse (G.), Balageas (D.), Carlomagno (G. M.) (Eds.), Quantitative infrared thermography, QIRT 96, Stuttgart, Edizione ETS, Pisa, 1997, p. 251-256.

[6] BUSSE (G.) - Optoacoustic phase angle measurement for probing a metal, Appl. Phys. Lett. 35, 1979, p. 759-760.

[7] THOMAS (R. L.), POUCH (J. J.), WONG (Y. H.), FAVRO (L. D.), KUO (P. K.), ROSENCWAIG (A.) - Subsurface flaw detection in metals by photoacoustic microscopy, J. Appl. Phys. 51, 1980, p. 1152-1156.

[8] LETHO (A.), JAARINEN (J.), TIUSANEN (T.), JOKINEN (M.), LUUKKALA (M.) -, Magnitude and phase in thermal wave imaging, Electr. Lett. 17, 1981, p. 364-365.

[9] BENNETT (C. A. Jr.), PATTY (R. R.) - Thermal wave interferometry: A potential application of the photoacoustic effect. In: Appl. Opt. 21, 1982, p. 49-54.

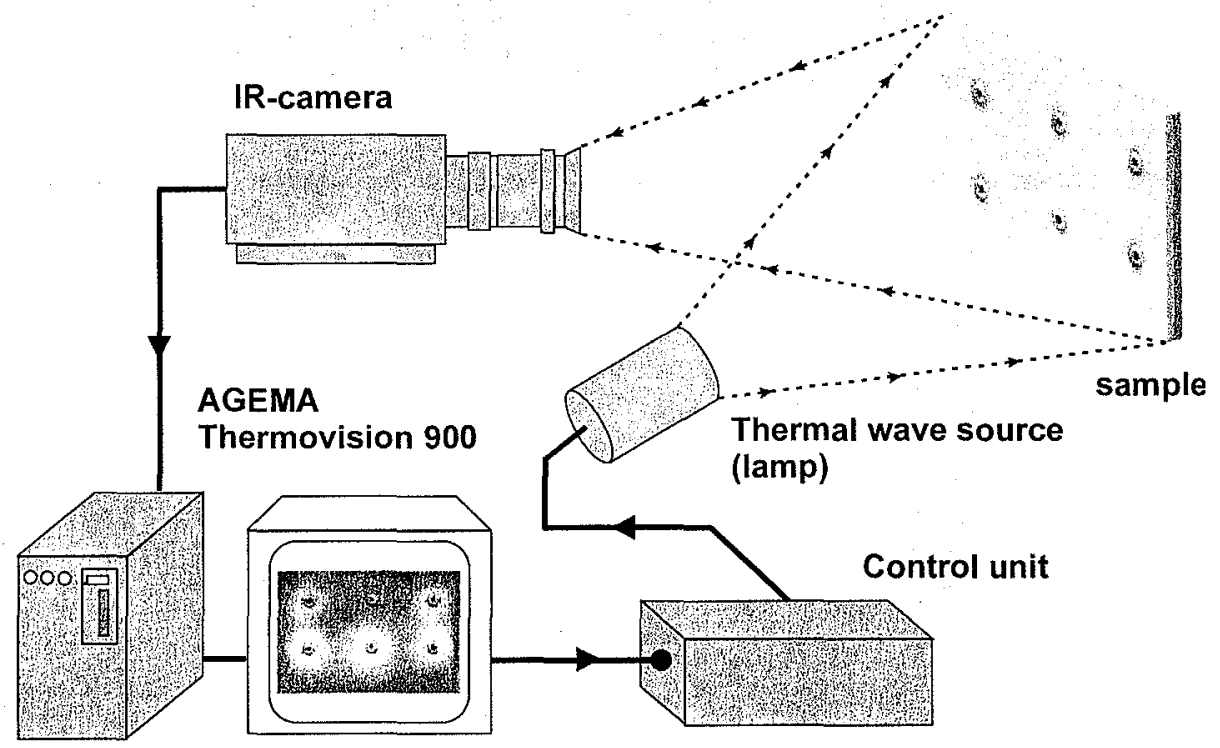

Fig. 1. Experimental arrangement 


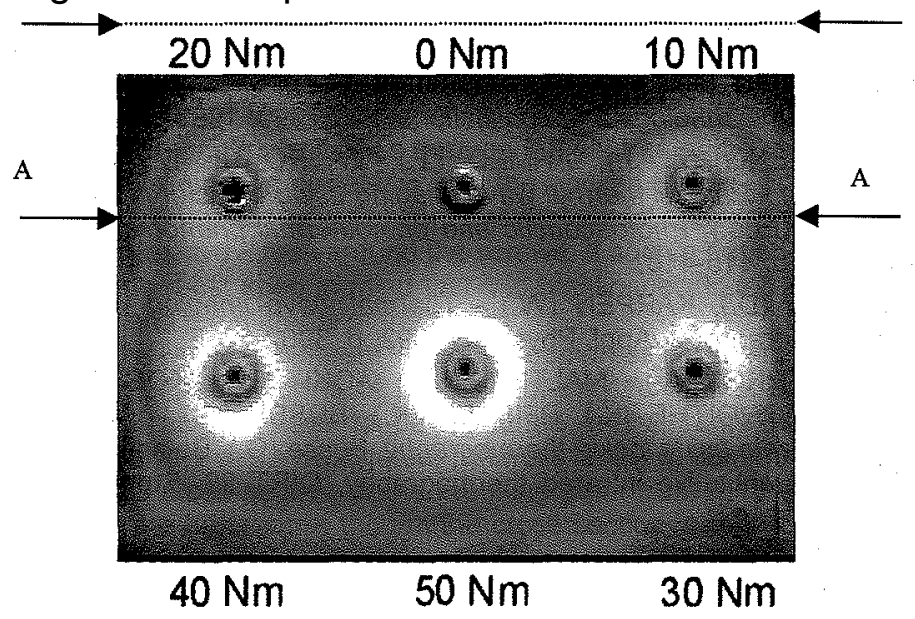

Fig. 2a. Phase image at a frequency of $0.06 \mathrm{~Hz}$ of nickelised steel plates (thickness $2 \mathrm{~mm}$ ) pressed together by screws that are fastened at different torque levels

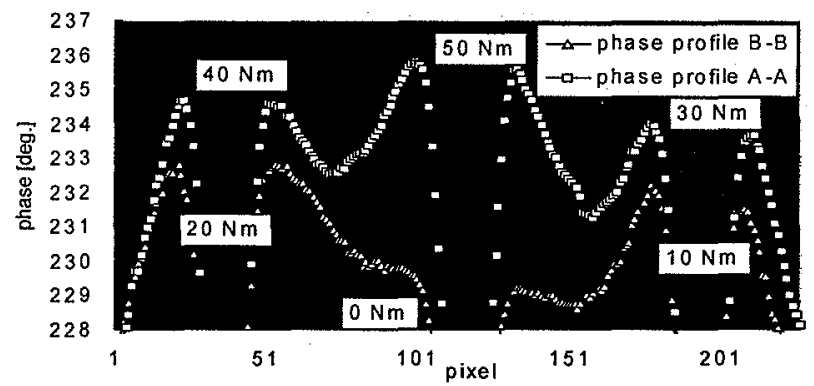

Fig. 2b. Phase profiles A-A (40 Nm - 50 Nm - $30 \mathrm{Nm})$ and B-B $(20 \mathrm{Nm}-0 \mathrm{Nm}-10 \mathrm{Nm})$

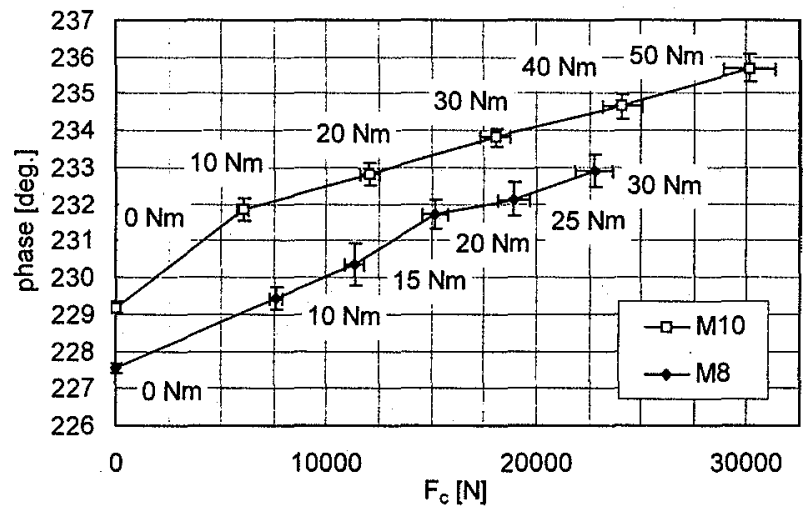

Fig. 2c. Correlation of phase values with different torque levels 
http://dx.doi.org/10.21611/qirt.1998.025

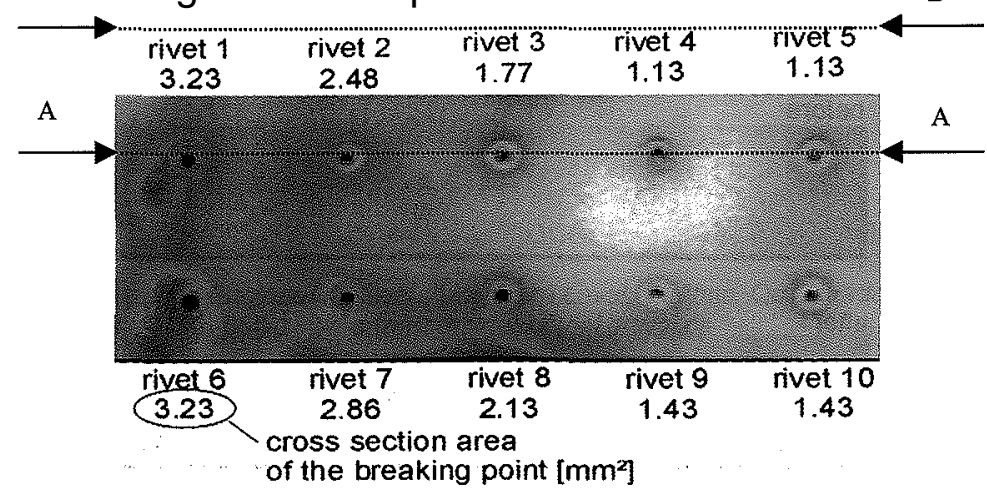

Fig. 3a. Phase image at a frequency of $0.06 \mathrm{~Hz}$ of two aluminium plates (thickness $1.5 \mathrm{~mm}$ ) pressed together by an array of 10 blind rivets with different cross sections.

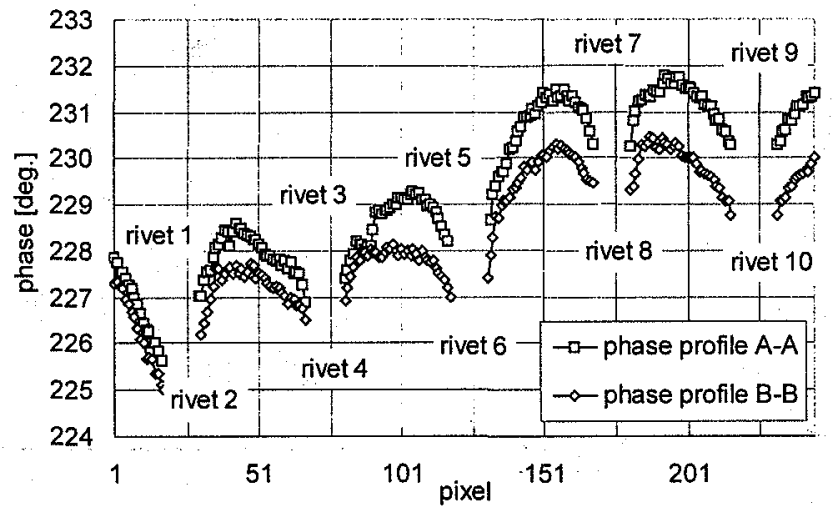

Fig. 3b. Phase profiles of the riveted sample

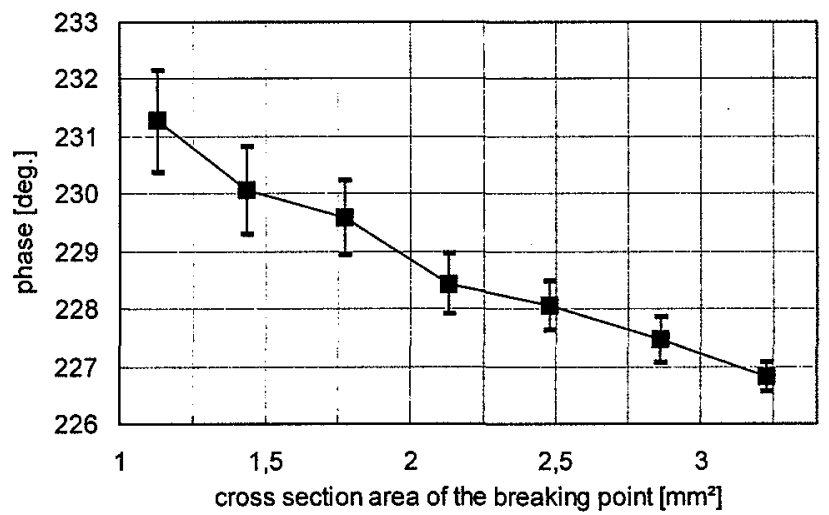

Fig. 3c. Correlation of phase values with different rivet tightness 
http://dx.doi.org/10.21611/qirt.1998.025

before

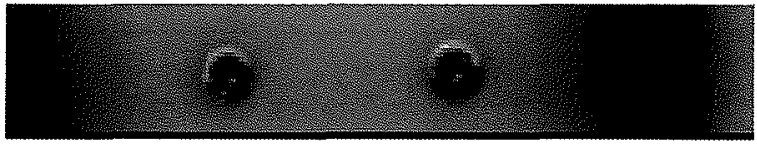

after

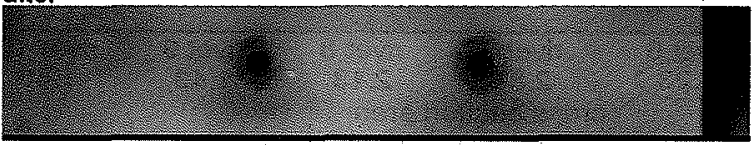

Fig.4. Phase image at a frequency of $0.06 \mathrm{~Hz}$ of a riveted sample before and after application of tensile stress

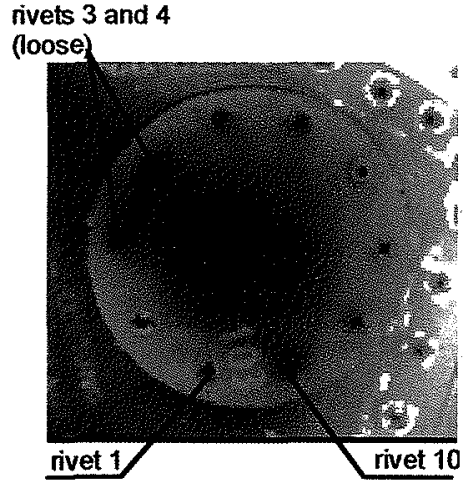

Fig.5. Phase image at a frequency of 0.03 $\mathrm{Hz}$ of a riveted aeroplane component

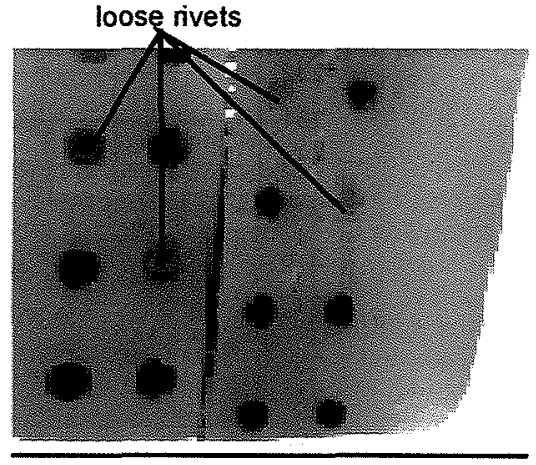

Fig.6. Phase image at a frequency of 0.06 $\mathrm{Hz}$ of a riveted aeroplane component 